九州大学学術情報リポジトリ

Kyushu University Institutional Repository

Formation of Unfertilized Small Seeds with Hard

Testa in Triploid Gape Hybrids (Vitis Complex)

Derived from Crosses between Diploid 'Muscat Bailey A' and Tetraploid 'Red Pearl'

Wakana, Akira

Faculty of Agriculture, Kyushu Unviersity

Sarikhani, Hassan

Graduate School of Bioresource and Bioenvironmental Sciences, Kyushu Unviersity

Hiramatsu, Michikazu

Faculty of Agriculture, Kyushu Unviersity

Hanada, Nobuak i

Faculty of Agriculture, Kyushu Unviersity

他

https://doi.org/10.5109/4674

出版情報: 九州大学大学院農学研究院紀要. 50 (2)，pp.607-614，2005-10-01. Faculty of Agriculture, Kyushu University

バージョン：

権利関係 : 


\title{
Formation of Unfertilized Small Seeds with Hard Testa in Triploid Gape Hybrids (Vitis Complex) Derived from Crosses between Diploid 'Muscat Bailey A' and Tetraploid 'Red Pearl'
}

\author{
Akira WAKANA*, Hassan SARIKHANI', Michikazu HIRAMATSU, \\ Nobuaki HANADA ${ }^{2}$ and Isao FUKUDOME ${ }^{2}$
}

\author{
Laboratory of Horticultural Science, Division of Agricultural Botany, Department of \\ Plant Resources, Faculty of Agriculture, Kyushu University, \\ Fukuoka 812-8581 \\ (Received June 30, 2005 and accepted July 26, 2005)
}

\begin{abstract}
To improve the fruit quality in triploid grapes, the mechanism underlying formation of unfertilized small seeds with hard seed coat was investigated in berries of a large number of triploid hybrids obtained from reciprocal crosses between diploid 'Muscat Bailey A' and tetraploid 'Red Pearl'. In each triploid hybrid plant, ten flower clusters trimmed so that they have about 200 flowers each were open-pollinated, and another ten open-pollinated flower clusters trimmed similarly were immersed in a solution of $\mathrm{GA}_{3}(100 \mathrm{mg} / \mathrm{l})$ at the full bloom stage. Triploid hybrid plants that produced unfertilized small seeds were $8 / 18$ plants for open-pollinated clusters and $21 / 68$ plants for $\mathrm{GA}_{3}$-treated clusters. The rate of unfertilized small seeds was different in different triploid hybrids, and the rates in each triploid plant showed small variation between two or three years examined. In $\mathrm{GA}_{3}$-treated clusters, the rate of small hard seeds in each hybrid was dramatically decreased. These results indicated that the extent of unfertilized small seed formation is a triploid-plant-specific character and that the formation is highly suppressed by immersion treatment of the flower clusters with high concentration of $\mathrm{GA}_{3}$ solution.
\end{abstract}

\section{INTRODUCTION}

Seedlessness in grape is one of the most desirable characters for consumers. In Japan, seedless berries have been commercially produced with the aid of twice treatments of gibberellin ( $\mathrm{GA}_{3} 100 \mathrm{mg} / \mathrm{l}$ for diploid and $25 \mathrm{mg} / \mathrm{l}$ for tetraploid cultivars) in seeded cultivars such as 'Delaware', 'Muscat Bailey A' and 'Pione'. However, the twice treatments with $\mathrm{GA}_{3}$ solution are tedious work for farmers. Therefore, it is essential for us to breed male and/or female sterile cultivars producing seedless berries.

In addition to breed stenospermocarpic seedless grapes (Winkler et al., 1962; Einset and Pratt, 1975; Mullins et al., 1992), breeding of triploid grapes has several superior points (Wakana et al., 2005). Triploid hybrid plants have been obtained from interploid

\footnotetext{
${ }^{1}$ Laboratory of Horticultural Science, Division of Agricultural Botany, Department of Plant Resources, Graduate School of Bioresource and Bioenvironmental Science, Faculty of Agriculture, Kyushu University

${ }^{2}$ Laboratory of Fruit Tree Science, University Farm, Faculty of Agriculture, Kyushu University, Fukuoka 811-2307

* Corresponding author (E-mail: wakana@agr.kyushu-u.ac.jp)
} 
crosses between diploid and tetraploid cultivars (Yamashita et al., 1993; Wakana et al., 2002) with high frequencies through in vitro culture of abortive young seeds and embryos (Yamashita et al., 1995, 1998; Wakana et al., 2003; Hiramatsu et al., 2003). Although these triploid hybrid plants showed low parthenocarpic ability, some of them produced high quality seedless berries with the aid of $\mathrm{GA}_{3}$ treatment at the anthesis (Wakana, et al., 2005). However, it became obvious that among them formation of unfertilized small seeds with hard testa occurred (Wakana, et al., 2005). Since the unfertilized small seed formation resulted in the deterioration of the seedless berry quality, we investigated the mechanism of small seed formation to improve the triploid berry quality and to develop triploid breeding in Vitis.

\section{MATERIALS AND METHODS}

\section{Plant materials}

Triploid hybrid grapes derived from reciprocal crosses between diploid 'Muscat Bailey A' and tetraploid 'Red Pearl' (Wakana et al., 2003 and 2005) were used to estimate the degree of unfertilized small seed formation. The triploid plants are complex intercontinental (European-American) hybrids with Vitis vinifera in their pedigrees. The triploid hybrid plants were derived through either embryo culture (Wakana et al., 2003) or immature seed culture and subsequent embryo culture (Hiramatsu et al., 2003). Eighteen triploid hybrid seedlings from 'Muscat Bailey A' $\times$ 'Red Pearl' and 68 from the reciprocal were used in this study. They were five- to seven-year-old trees grown in a greenhouse located at Sasaguri orchard of the University Farm, Kyushu University, Fukuoka.

Flower cluster thinning and $\mathrm{GA}_{3}$ treatment were carried out as has been reported previously (Wakana et al., 2005). More than ten trimmed flower clusters were treated with a solution of $100 \mathrm{mg} / \mathrm{GA}_{3}$ and another ten flower clusters were not treated with $\mathrm{GA}_{3}$. These flower clusters were open-pollinated.

\section{Analysis of small seeds}

Approximately ten mature clusters in each of $\mathrm{GA}_{3}-$ and non- $\mathrm{GA}_{3}$-treatments were harvested in each 3x hybrid plant about 100 days post-anthesis or in September of 1994, 1995, 1996 and 1997. The number of seeds was examined as to the difference between $\mathrm{GA}_{3}$ - and non-treated clusters and between the reciprocal crosses. The seeds were divided into two categories, large and small, based on the size of the seeds. The seeds were bisected with a surgical knife and the degree of embryo and endosperm development was observed under a magnifying glass.

\section{RESULT}

\section{Stability of small seed formation}

Ten of eighteen $3 x$ BR hybrids (56\%) from 'Muscat Bailey A' $\times$ 'Red Pearl' set berries in more than one clusters without $\mathrm{GA}_{3}$-treatment, while 47 of 68 3x RB hybrids (69\%) from the reciprocal cross set berries in more than one clusters without $\mathrm{GA}_{3}$ treatment. $\mathrm{GA}_{3}$ treatment resulted in berry set in all clusters of all the hybrids from the reciprocal crosses as has been reported previously (Wakana et al., 2005). 
Table 1. Comparison of rates of unfertilized small seeds between different years and between berries treated with $100 \mathrm{mg} / \mathrm{GA}_{3}$ and those without $\mathrm{GA}_{3}$ in eight triploid hybrid plants derived from 'Muscat Bailey A' $\times$ 'Red Pearl'. The rates of fertilized large seeds are also added in each year and in each treatment.

\begin{tabular}{|c|c|c|c|c|c|c|c|c|}
\hline \multirow{3}{*}{$\begin{array}{l}\text { Triploid } \\
\text { hybrid } \\
\text { No. } \\
\text { and } \\
\text { Year }\end{array}$} & \multicolumn{4}{|c|}{$\mathrm{GA}_{3}$-treated } & \multicolumn{4}{|c|}{ Non-treated } \\
\hline & \multirow{2}{*}{$\begin{array}{c}\text { No. of } \\
\text { clusters } \\
\text { examined }\end{array}$} & \multirow{2}{*}{$\begin{array}{c}\% \text { of } \\
\text { seeded } \\
\text { berries } \\
(\mathrm{N} / \mathrm{N})^{\mathrm{a}}\end{array}$} & \multicolumn{2}{|c|}{$\begin{array}{c}\text { No. of seeds } \\
\text { per } 100 \text { berries }\end{array}$} & \multirow{2}{*}{$\begin{array}{c}\text { No. of } \\
\text { clusters } \\
\text { examined }\end{array}$} & \multirow{2}{*}{$\begin{array}{c}\% \text { of } \\
\text { seeded } \\
\text { berries } \\
(\mathrm{N} / \mathrm{N})^{\mathrm{a}}\end{array}$} & \multicolumn{2}{|c|}{$\begin{array}{c}\text { No. of seeds } \\
\text { per } 100 \text { berries }\end{array}$} \\
\hline & & & Large & Small & & & Large & Small \\
\hline \multicolumn{9}{|l|}{ RB9001 } \\
\hline 1994 & 10 & $1.7(8 / 461)$ & 0.7 & 1.1 & 4 & $3.2(6 / 188)$ & 1.1 & 2.1 \\
\hline 1995 & 10 & $0 \quad(0 / 705)$ & 0 & 0 & 10 & $2.5(5 / 199)$ & 1.1 & 2.1 \\
\hline \multicolumn{9}{|l|}{ RB9006 } \\
\hline 1994 & 10 & $0 \quad(0 / 748)$ & 0 & 0 & 10 & $1.7(6 / 351)$ & 0 & 2.0 \\
\hline 1995 & 10 & $0 \quad(0 / 733)$ & 0 & 0 & 10 & $7.5(27 / 359)$ & 0.8 & 8.0 \\
\hline 1996 & 10 & $0.1(1 / 741)$ & 0.1 & 0 & 5 & $6.4(10 / 157)$ & 0 & 6.0 \\
\hline \multicolumn{9}{|l|}{ RB9013 } \\
\hline 1995 & 10 & $0 \quad(0 / 687)$ & 0 & 0 & 8 & $0.4(2 / 571)$ & 0.4 & 0.2 \\
\hline 1997 & 10 & $0.2(1 / 594)$ & 0.2 & 0 & 4 & $0 \quad(0 / 302)$ & 0 & 0 \\
\hline \multicolumn{9}{|l|}{ RB9025 } \\
\hline 1994 & 10 & $0 \quad(0 / 608)$ & 0 & 0 & 9 & $4.3(10 / 230)$ & 0.3 & 4.8 \\
\hline 1995 & 8 & $0.8(5 / 662)$ & 0.3 & 0.6 & 9 & $5.5(22 / 398)$ & 0.1 & 4.8 \\
\hline \multicolumn{9}{|l|}{ RB9028 } \\
\hline 1994 & 10 & $0.4(4 / 890)$ & 0 & 0.4 & 9 & $21.6(111 / 515)$ & 0 & 31.0 \\
\hline 1995 & 9 & $2.9(22 / 757)$ & 0 & 7.0 & 9 & $18.7(127 / 679)$ & 0.1 & 23.0 \\
\hline 1997 & 8 & $9.7(52 / 537)$ & 0 & 19.0 & \multicolumn{4}{|c|}{ not examined } \\
\hline \multicolumn{9}{|l|}{ RB9118 } \\
\hline 1994 & 10 & $2.7(17 / 636)$ & 0.1 & 6.0 & 10 & $37.7(58 / 154)$ & 0 & 136.0 \\
\hline 1995 & 10 & $0.1(1 / 694)$ & 0.6 & 0 & 8 & $10.2(18 / 177)$ & 2.8 & 16.0 \\
\hline \multicolumn{9}{|l|}{ RB9006 } \\
\hline 1994 & 10 & $0 \quad(0 / 748)$ & 0 & 0 & 10 & $1.7(6 / 351)$ & 0 & 1.7 \\
\hline 1995 & 10 & $0.1(0 / 733)$ & 0 & 0 & 10 & $7.5(27 / 359)$ & 0.8 & 5.8 \\
\hline 1996 & 10 & $0.1(1 / 741)$ & 0.1 & 0.1 & 5 & $6.4(10 / 157)$ & 0.6 & 3.4 \\
\hline
\end{tabular}

a No. of seeded berries / No. of berries set.

In the non-treated clusters, a few to a large number of unfertilized small seeds with hard seed coat were often observed among the hybrids from the reciprocal crosses. As compared with large seeds that rarely developed and often contained endosperm and embryo in the hybrids, all the small seeds did not have not only endosperm and embryo but also any trace of them. Thus, it is concluded from these observations that the small seeds are unfertilized.

The rate of small seeds forming in each of the $3 x$ hybrids was different for different hybrids and was relatively stable through the years examined, except for a small number of $3 \mathrm{x}$ hybrids showing large variations in different years in either $\mathrm{GA}_{3}$-treated and/or non-treated clusters (Table 1).

\section{Small seed formation in $3 \mathbf{x}$ BR hybrids}

Without $\mathrm{GA}_{3}$-treatment, eight of the 18 triploid hybrid plants did not set berries in all 
Table 2. Unfertilized small seed formation in non-GA,-treated berries of triploid hybrid grapes derived from 'Muscat Bailey A'(B) $\times$ 'Red Pearl'(R).

\begin{tabular}{|c|c|c|c|c|c|}
\hline $\begin{array}{l}\text { Triploid } \\
\text { hybrid }\end{array}$ & $\begin{array}{c}\text { No. of } \\
\text { clusters } \\
\text { examined }\end{array}$ & $\begin{array}{l}\text { No. of } \\
\text { berries }\end{array}$ & $\begin{array}{c}\text { No. of seeded } \\
\text { berries }(\%)\end{array}$ & $\begin{array}{r}\text { No. of large } \\
\text { seeds }\left(N^{b}\right)\end{array}$ & $\begin{array}{l}\text { No. of small } \\
\text { seeds }\left(\mathrm{N}^{\mathrm{c}}\right)\end{array}$ \\
\hline BR8604 & 1 & 151 & $15(24.2)$ & $0(0)$ & $18(29.0)$ \\
\hline BR9035" & 20 & 411 & 81 (19.7) & $3(0.7)$ & $116(28.2)$ \\
\hline BR9071 & 13 & 469 & $73(15.6)$ & $5(1.1)$ & $85(18.1)$ \\
\hline BR8956 & 9 & 456 & $41(9.0)$ & $2(0.4)$ & $42(9.2)$ \\
\hline BR8941 & 5 & 98 & $12(7.9)$ & $0(0)$ & $12(7.9)$ \\
\hline BR9101 & 3 & 48 & $2(4.2)$ & $0(0)$ & $4(8.3)$ \\
\hline BR9061 & 8 & 157 & $1(0.3)$ & $1(0.3)$ & $0(0)$ \\
\hline BR9102 & 6 & 623 & $0(0)$ & $0(0)$ & $0(0)$ \\
\hline BR9013 & 1 & 27 & $0(0)$ & $0(0)$ & $0(0)$ \\
\hline BR9077 & 1 & 4 & $0(0)$ & $0(0)$ & $0(0)$ \\
\hline Others $^{\mathrm{a}}$ & 0 & - & - & - & - \\
\hline
\end{tabular}

a BR8512, BR9006, BR9012, BR9019, BR9025, BR9088, BR9091 and BR9095. These flower clusters did not set without $\mathrm{GA}_{3}$-treatment. ' Average number of large seeds per 100 berries. " Average number of small seeds per 100 berries. ${ }^{\mathrm{A}} \mathrm{A}$ total of data for two years.

Table 3. Unfertilized small seed formation in $\mathrm{GA}_{3}$-treated berries of triploid hybrid grapes derived from 'Muscat Bailey A'(B) X 'Red Pearl'(R).

\begin{tabular}{|c|c|c|c|c|c|}
\hline $\begin{array}{l}\text { Triploid } \\
\text { hybrid }\end{array}$ & $\begin{array}{l}\text { No. of } \\
\text { clusters } \\
\text { examined }\end{array}$ & $\begin{array}{l}\text { No. of } \\
\text { berries }\end{array}$ & $\begin{array}{l}\text { No. of seeded } \\
\text { berries (\%) }\end{array}$ & $\begin{array}{l}\text { No. of large } \\
\text { seeds }\left(\mathrm{N}^{\mathrm{a}}\right)\end{array}$ & $\begin{array}{l}\text { No. of small seeds } \\
\qquad\left(N^{b} \leftarrow N^{c}\right)\end{array}$ \\
\hline BR9095 & 5 & 64 & $15(23.4)$ & $0(0)$ & 33 (51.6־non-set) \\
\hline BR9088 & 10 & 613 & $41(6.7)$ & $0(0)$ & 104 (17.0־non-set) \\
\hline BR9071 & 10 & 547 & $25(4.6)$ & $1(0.2)$ & $59(10.8 \leftarrow 18.1)$ \\
\hline BR9013 & 10 & 711 & $28(3.9)$ & $0(0)$ & $48(6.8 \leftarrow 0)$ \\
\hline BR9091 & 10 & 466 & $11(2.4)$ & $0(0)$ & $31(6.7 \leftarrow$ non-set) \\
\hline BR9012 & 3 & 78 & $3(3.8)$ & $0(0)$ & $3(3.9 \leftarrow$ non-set $)$ \\
\hline BR9035d & 20 & 997 & $3(0.3)$ & $1(0.1)$ & $5(0.5 \leftarrow 28.2)$ \\
\hline BR9101 & 10 & 394 & $3(0.8)$ & $0(0)$ & $3(0.8 \leftarrow 8.3)$ \\
\hline BR9061 & 10 & 366 & $1(0.3)$ & $1(0.3)$ & $0(0 \leftarrow 0)$ \\
\hline BR9077 & 10 & 335 & $1(0.3)$ & $1(0.3)$ & $0(0 \leftarrow 0)$ \\
\hline $\mathrm{BR}_{8956^{\mathrm{d}}}$ & 25 & 1526 & $1(0.1)$ & $1(0.1)$ & $0(0 \leftarrow 9.2)$ \\
\hline BR9006 & 8 & 968 & $0(0)$ & $0(0)$ & $0(0 \leftarrow$ non-set $)$ \\
\hline BR8941 & 9 & 553 & $0(0)$ & $0(0)$ & $0(0 \leftarrow \quad 7.9)$ \\
\hline BR8512 & 5 & 552 & $0(0)$ & $0(0)$ & $0(0 \leftarrow$ non-set $)$ \\
\hline BR8604 & 10 & 987 & $0(0)$ & $0(0)$ & $0(0 \leftarrow 29.0)$ \\
\hline BR9019 & 10 & 1294 & $0(0)$ & $0(0)$ & $0(0 \leftarrow$ non-set $)$ \\
\hline BR9102 & 10 & 623 & $0(0)$ & $0(0)$ & $0(0 \leftarrow \quad 0)$ \\
\hline BR9025 & 5 & 52 & $0(0)$ & $0(0)$ & $0(0 \leftarrow$ non-set $)$ \\
\hline
\end{tabular}

a Average number of large seeds per 100 berries. ' Average number of small seeds per 100 berries in $\mathrm{GA}_{3}$ treatment. " Average number of small seeds per 100 berries in non-treatment. " $\mathrm{A}$ total of data for two years. 
flower clusters. Six of the 18 triploid hybrid plants showed small seed formation in the small berries set without $\mathrm{GA}_{3}$-treatment (Table 2). In the six triploids, the rates of berries with large and/or small seeds ranged from 4.2 to $24.2 \%$, and number of small seeds per berry ranged from 0.08 to 0.29 . On the other hand, $\mathrm{GA}_{3}$-treatment to the flower clusters of the 18 triploid hybrids resulted in setting of enlarged berries in all the clusters treated (Table 3). Eleven of the 18 triploid plants produced seeded berries with the range from 0.1 to $23.4 \%$. Small seed formation was seen in eight of the eleven triploid plants with the range from 0.003 to 0.52 seed per berry. Compared with the number of small seed forming in berries setting without $\mathrm{GA}_{3}$-treatment, large berries setting with $\mathrm{GA}_{3}$ treatment showed very low rates of small seed formation, except for BR9013 wherein small seed formation ( 0.07 seed/berry) was seen in the large berries treated with $\mathrm{GA}_{3}$ but not in untreated small berries (Table 2 and 3). It seemed that this exceptional result is mainly due to the examination of only one cluster in the non-treatment.

\section{Small seed formation in $3 x$ RB hybrids}

Twenty-one of the 68 triploid RB hybrid plants derived from 'Red Pearl'×'Muscat

Table 4. Frequency distribution of $3 x$ hybrid plants producing berries with different $\%$ of small seeds and those containing different number of small seeds per berry in $\mathrm{GA}_{3}$-treated and non-treated berries of 68 triploid RB hybrid seedlings.

\begin{tabular}{|c|c|c|c|c|c|}
\hline \multicolumn{3}{|c|}{$\begin{array}{l}\text { No. of } 3 x \text { plants in indicated range of } \\
\% \text { berries with small seeds }\end{array}$} & \multicolumn{3}{|c|}{$\begin{array}{l}\text { No. of } 3 x \text { plants in indicated range of } \\
\text { small seed number per berry }\end{array}$} \\
\hline \multirow{2}{*}{$\begin{array}{c}\text { Range } \\
\text { (\% of berries } \\
\text { with small } \\
\text { seeds) }\end{array}$} & \multicolumn{2}{|c|}{ No. of $3 \times$ hybrid plants } & \multirow{2}{*}{$\begin{array}{l}\text { Range } \\
\text { (No. of small } \\
\text { seeds, } \times 10^{-2} \text { ) }\end{array}$} & \multicolumn{2}{|c|}{ No. of $3 \mathrm{x}$ hybrid plants } \\
\hline & $\begin{array}{l}\mathrm{GA}_{3} \text {-treated } \\
(\%)\end{array}$ & $\begin{array}{l}\text { Non-treated } \\
(\%)\end{array}$ & & $\begin{array}{c}\mathrm{GA}_{3}-\text { treated } \\
(\%)\end{array}$ & $\begin{array}{l}\text { Non-treated } \\
(\%)\end{array}$ \\
\hline 0 & $30(44.1)$ & $7(10.3)$ & 0 & $30(44.1)$ & 7 (10.3) \\
\hline $0<; \leqq 1$ & $19(27.9)$ & $4(5.9)$ & $0<; \leqq 1$ & $16(23.5)$ & $4(5.9)$ \\
\hline $1<; \leqq 2$ & $4(5.9)$ & $2(2.9)$ & $1<; \leqq 2$ & $4(5.9)$ & $2(2.9)$ \\
\hline $2<; \leqq 3$ & $4(5.9)$ & $6(8.8)$ & $2<; \leqq 3$ & $4(5.9)$ & $6(8.8)$ \\
\hline $3<; \leqq 4$ & $3(4.4)$ & $2(2.9)$ & $3<; \leqq 4$ & $3(4.4)$ & $2(4.4)$ \\
\hline $4<; \leqq 5$ & $1(1.5)$ & $4(5.9)$ & $4<; \leqq 5$ & $1(1.5)$ & $6(8.8)$ \\
\hline $5<; \leqq 6$ & $1(1.5)$ & $1(1.5)$ & $5<; \leqq 6$ & $2(2.9)$ & $1(1.5)$ \\
\hline $6<; \leqq 7$ & $0(0)$ & $2(2.9)$ & $6<; \leqq 7$ & $0(0)$ & $2(2.9)$ \\
\hline $7<; \leqq 8$ & $1(1.5)$ & $1(1.5)$ & $7<; \leqq 8$ & $2(2.9)$ & $0(0)$ \\
\hline $8<; \leqq 9$ & $0(0)$ & $1(1.5)$ & $8<; \leqq 9$ & $0(0)$ & $1(1.5)$ \\
\hline $9<; \leqq 10$ & $0(0)$ & $1(1.5)$ & $9<; \leqq 10$ & $0(0)$ & $1(1.5)$ \\
\hline $10<; \leqq 20$ & $5(7.4)$ & $8(11.8)$ & $10<; \leqq 20$ & $3(4.4)$ & $5(7.4)$ \\
\hline $20<; \leqq 30$ & $0(0)$ & $4(5.9)$ & $20<; \leqq 30$ & $1(1.5)$ & $2(2.9)$ \\
\hline $30<; \leqq 40$ & $0(0)$ & $0(0)$ & $30<; \leqq 40$ & 1 (1.5) & $4(4.6)$ \\
\hline $40<; \leqq 50$ & $0(0)$ & $0(0)$ & $40<; \leqq 50$ & $0(0)$ & $0(0)$ \\
\hline $50<; \leqq 60$ & $0(0)$ & . $2(2.9)$ & $50<; \leqq 60$ & $1(1.5)$ & $0(0)$ \\
\hline $60<; \leqq 70$ & $0(0)$ & $1(1.5)$ & $60<; \leqq 70$ & $0(0)$ & $0(0)$ \\
\hline $70<; \leqq 80$ & $0(0)$ & $1(1.5)$ & $70<; \leqq 80$ & $0(0)$ & $1(1.5)$ \\
\hline $80<; \leqq 90$ & $0(0)$ & $0(0)$ & $80<; \leqq 90$ & $0(0)$ & $3(4.4)$ \\
\hline Non-setting & $0(0)$ & $21(30.9)$ & Non-setting & $0(0)$ & $21(30.9)$ \\
\hline
\end{tabular}


Bailey A' did not produce berries in all non-treated flower clusters. Forty of the 68 triploid hybrid plants showed small seed formation in the berries setting without $\mathrm{GA}_{3}$-treatment (Table 4). In the 40 triploid plants, the rates of berries with small seeds ranged from 0.1 to $71.2 \%$, and number of small seeds per berry ranged from 0.001 to 0.87 . On the other hand, $\mathrm{GA}_{3}$-treatment to the flower clusters of the 68 triploid hybrids
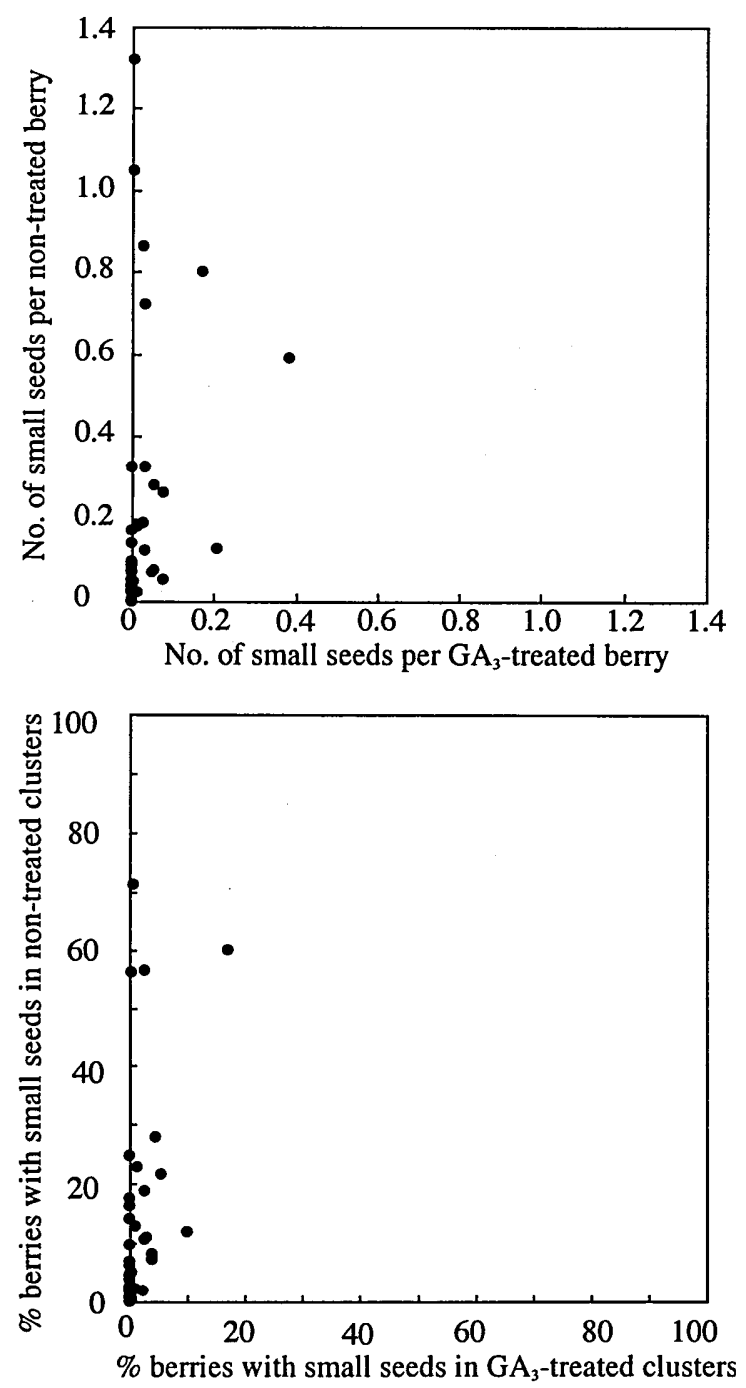

Fig. 1. Effect of $\mathrm{GA}_{3}$ treatment on the depression of unfertilized small seed formation in 38 triploid hybrid grapes derived from 'Red Pearl'X'Muscat Bailey A'. Upper: average number of unfertilized small seeds; lower: average rate (\%) of berries containing unfertilized small seeds. 
resulted in setting of berries in all the clusters treated (Table 4). Thirty-eight of the 68 triploid plants produced seeded berries with the range from 0.06 to $26.0 \%$. Small seed formation was seen in 30 of the 68 triploid plants with the range from 0.001 to 0.59 seed per berry. Compared with the number of small seeds forming in small berries setting without $\mathrm{GA}_{3}$-treatment, large berries setting with $\mathrm{GA}_{3}$ treatment showed very low rates of small seed formation (Fig. 1), as was observed in BR hybrid plants.

\section{DISCUSSION}

It is concluded from the present results that the small seeds with hard testa are unfertilized, since they were completely empty and very small in size and since the rate of berries with small seeds was different for different $3 \mathrm{x}$ hybrid plants with the range from 0 to 0.7 small seeds per berry. In the non-pollinated but $\mathrm{GA}_{3}$-treated flowers of triploid hybrid plants, for which emasculation and bagging treatment were carried out, resultant berries often produced unfertilized small seeds (unpublished), suggesting that the small seeds are completely unfertilized and developed to harden the integuments autonomously. The production of a great number of small seeds in berries of several triploid plants after self-pollination with sterile pollen lacking germination ability (Park et $a l ., 2002$ ) also suggests that the small seed formation is not related to fertilization but related to their autonomous ability. Furthermore, the present result indicates that fertilization and subsequent development of one of four or six ovules in a berry does not effect on development of the remaining three or five unfertilized ovules into small seeds, since in most cases only one large fertilized seed was contained in one berry without small seeds. The similar situation was also observed as to small seed formation, i.e., in most cases only one unfertilized small seed was contained in one berry. Why one of the four ovules usually developed into a small seed and why three of the four ovules remained undeveloped are not clear from the present results.

Wakana and Uemoto (1987) reported that in non-pollinated Citrus, unfertilized ovules autonomously developed to some extent and their integuments hardened, and that the degree of unfertilized ovule development and the degree of hardening of the integuments was different for different cultivars. In Vitis, the difference of the rates of small seed formation for different $3 \mathrm{x}$ hybrid plants and stability of the rate in individual $3 \mathrm{x}$ plant indicate that the ability to form small seed is under genetic control and the $3 \mathrm{x}$-hybrid-specific character. The similar frequency distribution of the triploid plants with different small seed formation rates in BR and RB hybrid plants also supports this conclusion. However, the exceptional cases, i.e., instability of the rates of small seed formation in different years, also suggests the possibility that some physiological and environmental factors such as tree vigor and temperature may affect the degree of unfertilized small seed formation.

Seed coat development and hardening has not been observed in fertilized but abortive ovules in stenospermocarpic cultivars such as 'Thompson Seedless'. This fact suggests that even after fertilization occurs in the ovules they do not develop and that their integuments do not harden. Thus, it may be concluded that the cultivars belonging to this type do not have or accumulate genes related to autonomous ovule development and subsequent integument hardening. Our results of unfertilized small seed formation in triploid 
grapes indicate that the usage of 'Muscat Bailey A' and 'Red Pearl' for breeding of stenospermocarpic seedless grapes may sometimes generate stenospermocarpic plants with the high ability of small seed formation.

In non- $\mathrm{GA}_{3}$-treated clusters, small seeds were contained in larger berries than those without small seeds, and the largest berries sometimes contained more than two small seeds. In a given triploid hybrid, however, the rate of small seeds formation decreased remarkably in large berries of $\mathrm{GA}_{3}$-treated clusters. These facts suggest that autonomous seed coat development in unfertilized ovules of $3 \mathrm{x}$ hybrid plants may be related to hormonal balance in the ovaries after pollination with the malfunction pollen, since the larger the size of berries in these $3 \mathrm{x}$ hybrid plants the more the small seeds were contained. Treatment of flowers with $100 \mathrm{mg} / 1 \mathrm{GA}_{3}$ solution seems to greatly reduce autonomous seed coat development because of its extremely higher concentration than that in natural conditions.

In conclusion, the present study suggests that, to produce fruit clusters consisting of perfectly seedless berries, elimination of factors controlling small seed formation is required for effective breeding program of triploid grapes, for that appropriate $\mathrm{GA}_{3}$ treatment and selection of parental cultivars with genetically very low ability of unfertilized small seed formation are important.

\section{REFERENCES}

Einset, J. and C. Pratt 1975 Grape. In “Advances in Fruit Breeding” ed. by J. Janick and J. N. Moore, Purdue Univ. Press, West Lafayette, pp. 130-153

Hiramatsu, M., A, Wakana, S. M. Park and I. Fukudome 2003 Production of triploid plants from crosses between diploid and tetraploid grapes (Vitis complex) through immature seed culture and subsequent embryo culture. J. Fac. Agr., Kyushu Univ., 48: 51-57

Mullins, M. G., A. Bouquet and L. E. Williams 1992 Biology of The Grapevine. Cambridge Univ. Press, Cambridge (England)

Park, S. M., A. Wakana, J. H. Kim and C. S. Jeong 2002 Male and female fertility in triploid grapes (Vitis complex) with special reference to the production of aneuploid plants. Vitis, 4: 11-19

Wakana, A., M. Hiramatsu, S. M. Park, H. Hanada, I. Fukudome and B. X. Ngo 2002 Degree of abortion and germination rates in triploid seeds from crosses between diploid and tetraploid grapes (Vitis vinifera L. and V. complex). J. Fac. Agr., Kyushu Univ., 46: 281-294

Wakana, A., M. Hiramatsu, S. M. Park, N. Hanada, I. Fukudome and K. Yasukochi 2003 Seed abortion in crosses between diploid and tetraploid grapes (Vitis vinifera and $V$. complex) and recover of triploid plants through embryo culture. J. Fac. Agr., Kyushu Univ., 48: 39-50

Wakana, A., S. M. Park, M. Hiramatsu, N. Hanada, I. Fukudome and K. Yasukochi 2005 Characteristics of seedless berries of triploid hybrid grapes (Vitis complex) from reciprocal crosses between diploid 'Muscat Bailey A' and tetraploid 'Red Pearl'. J. Fac. Agr., Kyushu Univ., 50: 49-59

Wakana, A. and S. Uemoto 1987 Adventive embryogenesis in Citrus. I Adventive embryo formation without pollination and fertilization. Amer. J. Bot., 74: 517-530

Winkler, A. J., J. A. Cook, W. M. Kliewer and L. A. Lider 1962 General viticulture. California Univ. Press, Berkley

Yamashita, H., S. Horiuchi and T. Taira 1993 Development of seeds and the growth of triploid seedlings obtained from reciprocal crosses between diploids and tetraploids grapes. J. Japan. Soc. Hort. Sci., 63: 349-255 (in Japanese with English summary)

Yamashita, H., T. Hanuda and H. Shiba 1995 In vitro culture of embryos obtained by crossing tetraploid cultivar Kyoho with diploid cultivars. J. Japan. Soc. Hort. Sci., 65: 719-724 (in Japanese with English summary)

Yamashita, H., I. Shigehara and T. Hanuda 1998 Production of triploid grapes by in ovulo embryo culture. Vitis, 37: 113-117 